\title{
Review
}

\section{Fibroblast Growth Factor 23 as a Therapeutic Target}

Fan Li, MD, MS; Zhousheng Xiao, MD, PhD*

Division of Nephrology, Department of Medicine, the University of Tennessee Health Science Center, Memphis, TN, 38I65, USA

\section{"Corresponding author}

Zhousheng Xiao, MD, PhD

Division of Nephrology, Department of Medicine, the University of Tennessee Health Science Center, Memphis,TN, 38I03, USA;Tel.(90I)-448-I489;

E-mail:szxao2@uthsc.edu

\section{Article Information}

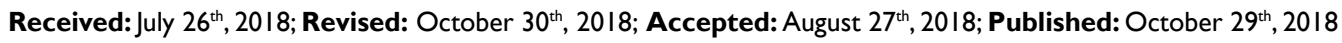

\section{Cite this article}

Li F, Xiao Z. Fibroblast growth factor 23 as a therapeutic target. Nephrol Open J. 2018; 4(I): I-6. doi: 10.17। 40/NPOJ-4-I I8

\section{ABSTRACT}

This fibroblast growth factor-23 (FGF-23) has been found as a circulating hormone and pathogenic factor in many disease conditions. This review focuses on recent advances in FGF-23 as a therapeutic target, including fibroblast growth factor receptors (FGFR) tyrosine kinase inhibitor, FGF-23 antibody, FGF-23 C-terminal peptide, CYP24A1 inhibitor, and FGF-23 antagonist. We also update the advantages and disadvantages of targeting upstream and downstream molecules in FGF-23 signaling pathways.

\section{INTRODUCTION}

$\mathrm{F}$ ibroblast growth factor-23 (FGF-23) is a bone-derived hormone that inhibits phosphate reabsorption and 1,25-dihydroxyvitamin D3 $(1,25(\mathrm{OH}) 2 \mathrm{D})$ production by the kidney ${ }^{1,2}$ (Figure 1). Physiologically, FGF-23 regulates systemic phosphate homeostasis and vitamin $\mathrm{D}$ metabolism through a bone-kidney axis. ${ }^{3,4}$ However, excess FGF-23 in genetic disorders leads to hypophosphatemic rickets as well as may play a pathogenic role in adverse outcomes in chronic kidney disease..$^{5-7}$ Primary increases in FGF-23 have been reported in rare hereditary hypophosphatemic disorders in humans and their mouse homologues, ${ }^{8-19}$ including X-linked hypophosphatemic rickets (XLH)/Hyp mice, caused by inactivating mutations of Phex, ${ }^{14,15,20}$ autosomal recessive hypophosphatemic rickets 1 (ARHR1), caused by inactivating mutations of Dmp $1,{ }^{15,20}$ ARHR2, caused by inactivating mutations in ENPP1, ${ }^{10,14}$ ${ }^{17}$ and Raine Syndrome (RNS), caused by inactivation mutations in FAM20C ${ }^{21,22}$ as well as tumor-induced osteomalacia (TIO). ${ }^{23-25}$ Secondary elevations of FGF-23 occurs in chronic kidney disease (CKD). ${ }^{1,26}$ Elevated FGF-23 is initially an adaptive response to altered mineral metabolism in chronic kidney disease $(\mathrm{CKD})^{27}$, but chronic elevations of FGF-23 are maladaptive and linked to increased morbidity and mortality, ${ }^{6}$ cardiovascular disease, ${ }^{6,28-31}$ and inflammation ${ }^{32,33}$ in CKD. Therefore, control of FGF-23 levels as well as its upstream and downstream signaling pathways could serve as a potential target to improve outcomes in many disease conditions. Currently, fibroblast growth factor receptors (FGFR) tyrosine kinase inhibitor (NVP-BGJ398), ${ }^{34,35}$ CYP24 $A 1$ inhibitor, ${ }^{36}$ FGF-23 antibody (KRN23), ${ }^{37,38}$ FGF-23C-terminal peptide, ${ }^{39,40}$ and FGF-23 antagonist ${ }^{41}$ are being developed to treat disorders of excess FGF-23. This review will summarize recent advances in these areas.

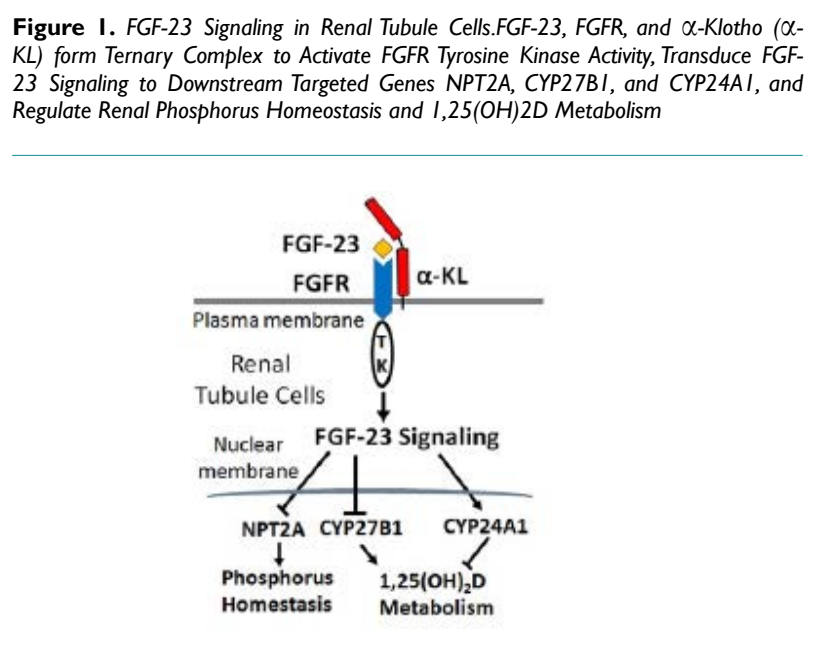

\section{FGFR KINASE INHIBITOR}

There is compelling evidence to support pharmacological inhibition of FGFRs in excess FGF-23. First, FGF-23 signaling is transduced by members of the FGF receptor (FGFRs, 1, 3, 4) family in conjunction with the essential co-receptor Klotho, which confers tissue-specificity for endocrine FGF-23 signals owing to its 
predominant expression in kidney (Figure 1). ${ }^{42}$ Second, hereditary hypophosphatemic disorders such as XLH/Hyp and ARHR1 involve activation of FGFR signaling and FGF-23 expression in osteocytes ${ }^{17}$ and osteocyte-specific deletion of Fgfr1 in $\mathrm{H}_{y p}$ mice markedly suppresses FGF-23 production. ${ }^{18}$ Third, a gainof-function mutation in FGFR1 causes osteoglophonic dysplasia (OGD), which is also associated with hypophosphatemia and elevated FGF-23 levels. ${ }^{43}$ Theoretically, it is useful to develop FGFR inhibitors that control FGF-23 signaling and production in disorders of excess FGF-23. In this regard, FGFR tyrosine kinase inhibitor (NVP-BGJ398) has been developed to treat FGF-23mediated hypophosphatemic diseases a and has been shown to block both the production and end-organ effects of FGF-23..$^{34,35}$ However, NVP-BGJ398 is a small molecule with potent inhibitory activity of FGFRs 1, 3, and 4 and lacks selectivity for FGF-23/ FGFR/ $\alpha$-KL signaling, and their generalized ability to inhibit FGFRs in multiple tissues would have undesirable effects. ${ }^{34,35}$ In addition, a small molecule, SSR128129E (SSR), which binds to the extracellular part of FGFR, was reported to act as a FGFR antagonist. $^{44,45}$ So far, SSR128129E are being developed as antitumor drugs since these compounds have limitations, including specificity and potential toxicities. At present, there are no small molecules that specifically modulate FGF-23 activation of FGFR/ $\alpha$-KL complexes. The discovery of such molecules would not only provide research tools to elucidate FGF-23 biological actions, but also would advance the discovery of new treatments based on this novel bone/kidney endocrine network.

\section{FGF-23 ANTIBODY}

A FGF-23 specific antibody [Burosumab, KRN23, Ultragenix (USA) and Kirin (Japan)] has been developed as a therapy for $\mathrm{XLH} .{ }^{37,38,46} \mathrm{KRN} 23$ binds to and inhibits the biological activity of FGF-23. However, loss of FGF-23 function can have serious side effects, including hyperphosphatemia and soft-tissue calcifications. Indeed, preclinical studies in CKD models show that inhibiting FGF-23 with a high affinity blocking antibody increased mortality, ${ }^{38}$ leading to no current plans to test KRN23 in CKD. Lowering FGF-23 in CKD is controversial, since use of calcimimetics to suppress PTH leads to modest reductions in FGF-23 and improved survival in patients with end-stage renal disease (ESRD) ${ }^{47}$ Since 30 million people or $15 \%$ of USA adults are estimated to have CKD and elevated FGF-23, ${ }^{48}$ identifying a drug to dose-dependently and reversibly reduce FGF-23 may improve CKD outcomes. To avoid toxicity, a low affinity FGF-23 blocking antibody (KRN23) was selected for clinical development. Clinical trials with KRN23 show efficacy to raise serum phosphate and improve rickets in $\mathrm{XLH}{ }^{37,38}$ Although hyperphosphatemia occurred in $\sim 6 \%$ of the KRN23 treated XLH patients, biologics such as KRN23 are plagued by high cost, the need for parenteral delivery, long half-life, and difficulty with dose titration. From the business perspective, there is an opportunity to develop a small, orally bioavailable small molecule to inhibit FGF-23.

\section{FGF-23 C-TERMINAL PEPTIDES |}

Full-length FGF-23 is a $32-\mathrm{kDa}$ protein that can be cleaved at 176RXXR179 site by a cellular endoproteasefur in, leading to the
22-kDa N-terminal and 16-kDa C-terminal fragments. ${ }^{13}$ Recent studies have shown that the C-terminal tail of FGF-23 (FGF-23C) can compete with full-length ligand for binding to the FGFR/ $\alpha$ KL complex, and hence can antagonize the phosphaturic activity of FGF-23 in vivo, both in healthy rats and in a mouse model of phosphate wasting disorders. ${ }^{39,40}$ In order to increase the half-life of the FGF-23C peptide, the investigators generated a FGF-23C Fc fusion molecule and demonstrated that repeated injection of this molecule (twice a week, $10 \mathrm{mg} / \mathrm{kg}$ ) selectively modulates the phosphate pathway via regulation of NPT2 $A$ expression in vivo by competitive antagonism of FGF-23 binding to the FGFR/ $\alpha-\mathrm{KL}$ co-receptor in Hypmice, a preclinical model of XLH.The unique ability of FGF-23C Fc molecule to preferentially modulate the FGFR1/ $\alpha$-KL phosphate pathway but not FGFR3 $\& 4 / \alpha-\mathrm{KL}$ in the control of $1,25(\mathrm{OH}) 2 \mathrm{D}$ levels in kidney makes this molecule ideal foruse as a new the rapeutic in the treatment of XLH, with thepotential to significantly improve bone formation in XLH patients with limited safety concerns. ${ }^{39,40}$

\section{CYP24AI INHIBITOR}

FGF-23 impairs the production of renal 1,25(OH)2D through either inhibiting the expression of CYP27B1, the enzyme that converts $25-(\mathrm{OH}) \mathrm{D}$ to its active metabolite, or upregulating the expression of vitamin D 24-hydroxylase (CYP24A1), a mitochondrial enzyme responsible for inactivating vitamin $\mathrm{D}$ metabolites through the $\mathrm{C}-24$ oxidation pathway. ${ }^{49}$ In the overexpressing mutant FGF23R176Q and $H y p$ mouse models, hypophosphatemic ricketswith high levels of FGF-23 are also associated with increased renal CYP24A1 expression, suggesting that elevated CYP24 A1 activity is pivotal to the pathophysiology of these disorders. ${ }^{50,51}$ Knockout of CYP24A1 in the Hyp and FGF23R176Q-transgenic miceresulted in near-complete recovery of rachitic bony abnormalities, but serum levels of phosphorus and 1,25(OH)2D did not improve in these murine models of human disease. ${ }^{36}$ Interestingly, treatment of Hyp and FGF23R176Q-transgenic mice with the CYP24A1 inhibitor CTA102 also ameliorated their rachitic bones. ${ }^{36}$ Whether pharmacologic inhibition of CYP24A1 activity goes solo as a therapeutic target remains to be further investigated.

\section{FGF-23 ANTAGONIST |}

In addition to FGF-23 specific antibody and FGF-23 C peptide, a computationally identified FGF-23 antagonist (ZINC13407541) was found to bind to FGF-23 that disrupts its interaction with the FGFR/ $\alpha-\mathrm{KL}$ complex in a heterologous cell expression system. ${ }^{41}$ This FGF-23 antagonist was also shown to inhibit FGF-23 signaling in isolated renal tubules ex vivo and to increase serum phosphate and $1,25(\mathrm{OH}) 2 \mathrm{D}$ in a mouse model of FGF23 -related hypophosphatemic diseases. ${ }^{41}$ In addition, this FGF-23 antagonist slightly but significantly reduced FGF-23 levels along with increased PTH levels in mouse disease model. ${ }^{41}$ The findings of small molecule that antagonizes FGF-23 activation of FGFRs provide a new tool to probe the functions of FGF-23 and set the stage for developing clinical drug candidates to treat disorders of excess FGF-23. Furthermore FGF-23 antagonist can be costeffective, orally bioavailable and easily dose titration compared to the FGF-23 antibody. This small molecule has been using to 


\begin{tabular}{|c|c|c|c|}
\hline Reagent & Mechanism of Action & Positive/Negative Aspects & References \\
\hline $\begin{array}{l}\text { FGFR Kinase Inhibi- } \\
\text { tor }\end{array}$ & $\begin{array}{l}\text { Inhibition of FGFR tyrosine } \\
\text { kinase }\end{array}$ & $\begin{array}{l}\text { Blocking both the production } \\
\text { and end-organ effects of FGF- } \\
23 / \text { no specificity }\end{array}$ & 34,35 \\
\hline FGF-23 Antibody & Function blocking & $\begin{array}{l}\text { High specificity of treatment } \\
\text { and dose titratibility/Cost and } \\
\text { parenteral delivery }\end{array}$ & 37,38 \\
\hline $\begin{array}{l}\text { FGF-23 C-terminal } \\
\text { Peptides }\end{array}$ & $\begin{array}{l}\text { Competitive antagonism of } \\
\text { FGF- } 23 \text { binding }\end{array}$ & $\begin{array}{l}\text { High specificity of treatment/ } \\
\text { the increased proteolytic insta- } \\
\text { bility during treatment }\end{array}$ & 39,40 \\
\hline CYP24AI Inhibitor & $\begin{array}{l}\text { Inhibition of CYP24AI activ- } \\
\text { ity }\end{array}$ & $\begin{array}{l}\text { Recovery of rachitic bone/no } \\
\text { effect on levels of phosphorus } \\
\text { and } I, 25(\mathrm{OH}) 2 \mathrm{D}\end{array}$ & 36 \\
\hline FGF-23 Antagonist & $\begin{array}{l}\text { Disruption of FGF- } 23 \text { binding } \\
\text { to FGFR/ } \alpha-K L \text { complex }\end{array}$ & $\begin{array}{l}\text { Orally bioavailable, dose titrat- } \\
\text { ibility, and cost-effective/Short } \\
\text { half-time }\end{array}$ & 41 \\
\hline
\end{tabular}

develop lead compound for preclinical screening and late clinical trials.

\section{THE POTENTIAL SIDE EFFECTS OF THESEFGF-23TARGET EDTHERAPIES}

As shown in Table 1, all of current FGF-23 targeted therapies have their advantages and disadvantages. The FGFR inhibitors show a strong inhibition of FGFR tyrosine kinase activity; these compounds can block both the production and end-organ effects of FGF-23, but demonstrate no specificity and potential tissue and organ toxicity. In contrast, FGF-23 antibody plays a function blocking on FGF-23and displays a high specificity of treatment. However, FGF-23 antibodyneeds parenteral delivery and high cost treatment. FGF-23 C-terminal peptides also have a high specificity of treatment, but the increased proteolytic instability during treatment would limit its use as a long-time therapeutic strategy. ${ }^{52}$ CYP24A1 inhibitor almost completely recover rachitic bone of hypophosphatemic disorder, but this compound has no effect on levels of phosphorus and 1,25(OH)2D. FGF-23 antagonist could be a promising therapeutic strategy because of

effective, orally bioavailable and easily dose titration compared to the FGF-23 antibody. This small molecule has been using to develop lead compound for preclinical screening and late clinical trials.

\section{THE POTENTIAL SIDE EFFECTS OF THESEFGF-23TARGET EDTHERAPIES}

As shown in Table 1, all of current FGF-23 targeted therapies have their advantages and disadvantages. The FGFR inhibitors show a strong inhibition of FGFR tyrosine kinase activity; these compounds can block both the production and end-organ effects of FGF-23, but demonstrate no specificity and potential tissue and organ toxicity. In contrast, FGF-23 antibody plays a function blocking on FGF-23and displays a high specificity of treatment. However, FGF-23 antibody needs parenteral delivery and high cost treatment. FGF-23 C-terminal peptides also have a high specificity of treatment, but the increased proteolytic instability during treatment would limit its use as a long-time therapeutic strategy. ${ }^{52}$ CYP24A1 inhibitor almost completely recover rachitic bone of hypophosphatemic disorder, but this compound has no effect on levels of phosphorus and 1,25(OH)2D. FGF-23 antagonist could be a promising therapeutic strategy because of its oral bioavailability, dose titratibility, and cost-effective if the optimization overcomes the short half time of the compound.

\section{CONCLUSION}

Fibroblast growth factor-23 is a circulating hormone that regulates phosphate and vitamin D metabolism. Excess actions of FGF-23 result in reductions in serum phosphate and 1,25(OH)2D levels and hypophosphatemi crickets. Therefore, it is necessary to develop therapeutic methods to suppress the activities of thathorm one. In fact, patients with hypophosphatemic disorders by FGF-23 excess were reported to benefit from FGF-23 blocking antibodies or inhibitors of FGF-23 signaling. ${ }^{37,53,54}$ However, these therapies need careful monitoring dosing-use because deficient actions of FGF23 result in hyperphosphatemic disease. ${ }^{55,56}$ Indeed, management of FGF-23 levelsin patients with CKD seems to be debatable since modest reductions in FGF-23 with calcimimetics could improve survival in patients with ESRD ${ }^{47}$ while inhibiting FGF-23 with a high affinity blocking antibody increased mortality in $\mathrm{CKD},{ }^{38}$ leading to questionable benefit from these novel therapies in CKD. However, use of either low affinity FGF-23 antibody or FGF-23 inhibitors to control FGF-23 excess actions remains a promising therapy for both hereditary and acquired hyperphosphatemic diseases.

\section{CONFLICTS OF INTEREST|}

The authors declare that they have no conflicts of interest.

\section{REFERENCES}

1. Weber TJ, Liu S, Indridason OS, Quarles LD. Serum FGF23 levels in normal and disordered phosphorus homeostasis. J Bone Miner Res. 2003; 18:1227-1234. doi: 10.1359/jbmr.2003.18.7.1227

2. Yamashita T, Yoshioka M, Itoh N. Identification of a novel 
fibroblast growth factor, FGF-23, preferentially expressed in the ventrolateral thalamic nucleus of the brain. Biochem Biophys Res Commun. 2000; 277: 494-498. doi: 10.1006/bbrc.2000.3696

3. Liu S, Gupta A, Quarles LD. Emerging role of fibroblast growth factor-23 in a bone-kidney axis regulating systemic phosphate homeostasis and extracellular matrix mineralization. Curr Opin Nephrol Hypertens. 2007; 16: 329-335. doi: 10.1097/ MNH.0b013e3281ca6ffd

4. Quarles LD. The bone and beyond: 'Dem bones' are made for more than walking. Nat Med. 2011; 17: 428-430. doi: 10.1038/ nm0411-428

5. Faul C, Amaral AP, Oskouei B, et al. FGF-23 induces left ventricular hypertrophy, J Clin Invest. 2011; 121: 393-408. doi: 10.1172/JCI46122

6. Gutierrez OM, Mannstadt M, Isakova T, et al. Fibroblast growth factor-23 and mortality among patients undergoing hemodialysis. N Engl J Med. 2008; 359: 584-592. doi: 10.1056/NEJMoa0706130 7. Olauson H, Larsson TE. FGF23 and Klotho in chronic kidney disease. Curr Opin Nephrol Hypertens. 2013; 22: 397-404. doi: 10.1097/MNH.0b013e32836213ee

8. Quarles LD. FGF23, PHEX, and MEPE regulation of phosphate homeostasis and skeletal mineralization. Am J Physiol Endocrinol Metab. 2003; 285: e1-e9. doi: 10.1152/ajpendo.00016.2003

9. Mackenzie NC, Zhu D, Milne EM, et al. Altered bone development and an increase in FGF-23 expression in Enpp1(/-) mice. PLoS One. 2012; 7: e32177. doi: 10.1371/journal. pone. 0032177

10. Han X, Li L, Yang J, King G, Xiao Z, Quarles LD. Counterregulatory paracrine actions of FGF-23 and 1,25(OH)2 D in macrophages. FEBS Lett. 2016; 590: 53-67. doi: 10.1002/18733468.12040

11. Han X, Xiao Z, Quarles LD. Membrane and integrative nuclear fibroblastic growth factor receptor (FGFR) regulation of FGF-23. J Biol Chem. 2015; 290: 10447-10459. doi: 10.1074/jbc. M114.609230

12. Liu S, Guo R, Simpson LG, Xiao ZS, Burnham CE, Quarles LD. Regulation of fibroblastic growth factor-23 expression but not degradation by PHEX. J Biol Chem. 2003; 278: 37419-37426. doi: 10.1074/jbc.M304544200

13. Liu S, Zhou J, Tang W, Jiang X, Rowe DW, Quarles LD. Pathogenic role of Fgf-23 in Hyp mice. Am J Physiol Endocrinol Metab. 2006; 291: E38-E49. doi: 10.1152/ajpendo.00008.2006

14. Liu S, Zhou J, Tang W, Menard R, Feng JQ, Quarles LD. Pathogenic role of Fgf-23 in Dmp1-null mice. Am J PhysiolEndocrinol Metab. 2008; 295: E254-E261. doi: 10.1152/ajpendo.90201.2008
15. Wang X, Wang S, Li C, et al. Inactivation of a novel FGF23 regulator, FAM20C, leads to hypophosphatemic rickets in mice. PLoS genet. 2012; 8: e1002708. doi: 10.1371/journal.pgen.1002708

16. Martin A, Liu S, David V, et al. Bone proteins PHEX and DMP1 regulate fibroblastic growth factor Fgf-23 expression in osteocytes through a common pathway involving FGF receptor (FGFR) signaling. FASEB J. 2011; 25: 2551-2562. doi: 10.1096/ fj.10-177816

17. Xiao Z, Huang J, Cao L, Liang Y, Han X, Quarles LD. Osteocyte-specific deletion of Fgfr1 suppresses FGF-23. PLoS One. 2014; 9: e104154. doi: 10.1371/journal.pone.0104154

18. Zhang Q, Doucet M, Tomlinson RE, et al. The hypoxiainducible factor-1alpha activates ectopic production of fibroblast growth factor-23 in tumor-induced osteomalacia. Bone Res. 2016; 4: 16011. doi: 10.1038/boneres.2016.11

19. Feng JQ, Ward LM, Liu S, et al. Loss of DMP1 causes rickets and osteomalacia and identifies a role for osteocytes in mineral metabolism. Nat Genet. 2006; 38: 1310-1315. doi: 10.1038/ng1905

20. Wang X., Wang S, Li C, et al. Inactivation of a novel FGF23 regulator, FAM20C, leads to hypophosphatemic rickets in mice. PLoS Genet. 2012; 8: e1002708. doi: 10.1371/journal.pgen.1002708

21. Whyte MP, McAlister WH, Fallon MD, et al. Raine syndrome (OMIM \#259775), caused by FAM20C mutation, is congenital sclerosing osteomalacia with cerebral calcification (OMIM 259660). J Bone Miner Res. 2016; 32: 757-769. doi: 10.1002/jbmr.3034

22. Oya K, Ishida K, Nishida T, et al. Immunohistochemical analysis of dentin matrix protein 1 (DMP1) phosphorylation by Fam20C in bone: Implications for the induction of biomineralization. Histochem Cell Biol. 2016; 147: 341-351. doi: 10.1007/s00418-016$1490-\mathrm{z}$

23. Shimada T, Mizutani S, Muto T, et al. Cloning and characterization of FGF23 as a causative factor of tumor-induced osteomalacia. Proc Natl Acad Sci U S A. 2001; 98: 6500-6505. doi: 10.1073/pnas. 101545198

24. Fukumoto S. Yamashita T. Fibroblast growth factor-23 is the phosphaturic factor in tumor-induced osteomalacia and may be phosphatonin. Curr Opin Nephrol Hypertens. 2002; 11: 385-389. doi: 10.1097/00041552-200207000-00003

25. White KE, Jonsson KB, Carn G, et al. The autosomal dominant hypophosphatemic rickets (ADHR) gene is a secreted polypeptide overexpressed by tumors that cause phosphate wasting. J Clin Endocrinol Metab. 2001; 86: 497-500. doi: 10.1210/jcem.86.2.7408

26. Komaba H, Fukagawa M. The role of FGF23 in CKD--with or without Klotho. Nat Rev Nephrol. 2012; 8: 484-490. doi: 10.1038/ nrneph.2012.116 
27. Quarles LD. Evidence for a bone-kidney axis regulating phosphate homeostasis. J Clin Invest. 2003; 112: 642-646. doi: 10.1172/JCI200319687

28. Gutierrez OM, Januzzi JL, Isakova T, et al. Fibroblast growth factor-23 and left ventricular hypertrophy in chronic kidney disease. Circulation. 2009; 119: 2545-2552. doi: 10.1161/ CIRCULATIONAHA.108.844506

29. Isakova T, Xie H, Yang W, et al. Fibroblast growth factor-23 and risks of mortality and end-stage renal disease in patients with chronic kidney disease. JAMA. 2011; 305: 2432-2439. doi: 10.1001/jama.2011.826

30. Hsu HJ, Wu MS. Fibroblast growth factor-23: A possible cause of left ventricular hypertrophy in hemodialysis patients. Am J Med Sci. 2009; 337: 116-122. doi: 10.1097/MAJ.0b013e3181815498

31. Jean G, Bresson E, Terrat JC, et al. Peripheral vascular calcification in long-haemodialysis patients: Associated factors and survival consequences. Nephrol Dial Transplant. 2009; 24: 948-955. doi: $10.1093 /$ ndt/gfn571

32. Munoz Mendoza J, Isakova T, Ricardo AC, et al. Fibroblast growth factor-23 and Inflammation in CKD. Clin J Am Soc Nephrol. 2012; 7: 1155-1162. doi: 10.2215/CJN.13281211

33. Hanks LJ, Casazza K, Judd SE, Jenny NS, Gutierrez OM. Associations of fibroblast growth factor-23 with markers of inflammation, insulin resistance and obesity in adults. PLoS One. 2015; 10: e0122885. doi: 10.1371/journal.pone.0122885

34. Wöhrle S, Henninger C, Bonny $\mathrm{O}$, et al. Pharmacological inhibition of fibroblast growth factor (FGF) receptor signaling ameliorates FGF23-mediated hypophosphatemic rickets. J Bone Miner Res. 2013; 28: 899-911. doi: 10.1002/jbmr.1810

35. Wöhrle S, Bonny O, Beluch N, et al. FGF receptors control vitamin $\mathrm{D}$ and phosphate homeostasis by mediating renal FGF-23 signaling and regulating FGF-23 expression in bone. J Bone Miner Res. 2011; 26: 2486-2497. doi: 10.1002/jbmr.478

36. Bai X, Miao D, Xiao S, et al. CYP24 inhibition as a therapeutic target in FGF23-mediated renal phosphate wasting disorders. J Clin Invest. 2016; 126: 667-680. doi: 10.1172/JCI81928

37. Carpenter TO, Imel EA, Ruppe MD, et al. Randomized trial of the anti-FGF23 antibody KRN23 in X-linked hypophosphatemia, J Clin Invest. 2014; 124: 1587-1597. doi: 10.1172/JCI72829

38. Shalhoub V, Shatzen EM, Ward SC, et al. FGF23 neutralization improves chronic kidney disease-associated hyperparathyroidism yet increases mortality. J Clin Invest. 2012; 122: 2543-2553. doi: 10.1172/JCI61405

39. Goetz R, Nakada Y, Hu MC, et al. Isolated C-terminal tail of FGF23 alleviates hypophosphatemia by inhibiting FGF23-FGFRKlotho complex formation. Proc Natl Acad Sci U S A. 2010; 107:
407-412. doi: 10.1073/pnas.090200610

40. Johnson K, Levine K, Sergi J, et al. Therapeutic effects of FGF23 c-tail Fc in a murine preclinical model of X-linked hypophosphatemia via the selective modulation of phosphate reabsorption. J Bone Miner Res. 2017; 32: 2062-2073. doi: 10.1002/ jbmr.3197

41. Xiao Z, Riccardi D, Velazquez HA, et al. A computationally identified compound antagonizes excess FGF-23 signaling in renal tubules and a mouse model of hypophosphatemia. Sci Signal. 2016; 9: ra113. doi: 10.1126/scisignal.aaf5034

42. Urakawa I, Yamazaki Y, Shimada T, et al. Klotho converts canonical FGF receptor into a specific receptor for FGF23. Nature. 2006; 444: 770-774. doi: 10.1038/nature05315

43. White KE, Cabral JM, Davis SI, et al. Mutations that cause osteoglophonic dysplasia define novel roles for FGFR1 in bone elongation. Am J Hum Genet. 2005; 76: 361-367. doi: $10.1086 / 427956$

44. Herbert C, Schieborr U, Saxena K, et al. Molecular mechanism of SSR128129E, an extracellularly acting, small-molecule, allosteric inhibitor of FGF receptor signaling. Cancer Cell. 2013; 23: 489-501. doi: 10.1016/j.ccr.2013.02.018

45. Herbert C, Schieborr U, Saxena K, et al. Molecular mechanism of SSR128129E, an extracellularly acting, small-molecule, allosteric inhibitor of FGF receptor signaling. Cancer Cell. 2016; 30: 176-178. doi: $10.1016 /$ j.ccell.2016.06.015

46. Aono Y, Yamazaki Y, Yasutake J, et al. Therapeutic effects of anti-FGF23 antibodies in hypophosphatemic rickets/osteomalacia. J Bone Miner Res. 2009; 24: 1879-1888. doi: 10.1359/jbmr.090509

47. Moe SM, Chertow GM, Parfrey PS, et al. Cinacalcet, fibroblast growth factor-23, and cardiovascular disease in hemodialysis: The evaluation of cinacalcet $\mathrm{HCl}$ therapy to lower cardiovascular events (EVOLVE) trial. Circulation. 2015; 132: 27-39. doi: 10.1161/ CIRCULATIONAHA.114.013876

48. Murphy D, McCulloch CE, Lin F, et al. Trends in prevalence of chronic kidney disease in the United States. Ann Intern Med. 2016; 165: 473-481. doi: 10.7326/M16-0273

49. Bai XY, Miao D, Goltzman D, Karaplis AC. The autosomal dominant hypophosphatemic rickets R176Q mutation in fibroblast growth factor 23 resists proteolytic cleavage and enhances in vivo biological potency. J Biol Chem. 2003; 278: 9843-9849. doi: 10.1074/ jbc.M210490200

50. Bai X, Miao D, Li J, Goltzman D, Karaplis AC. Transgenic mice overexpressing human fibroblast growth factor 23 (R176Q) delineate a putative role for parathyroid hormone in renal phosphate wasting disorders. Endocrinology. 2004; 145: 5269-5279. doi: 10.1210/en.2004-0233 
51. Beck L, Soumounou Y, Martel J, et al. Pex/PEX tissue distribution and evidence for a deletion in the 3' region of the Pex gene in X-linked hypophosphatemic mice. J Clin Invest. 1997; 99: 1200-1209. doi: 10.1172/JCI119276

52. Otvos L, Wade JD. Current challenges in peptide-based drug discovery. Front Chem. 2014; 2: 62 doi: 10.3389/fchem.2014.00062

53. Florenzano P, Gafni RI, Collins MT. Tumor-induced osteomalacia. Bone Rep. 2017; 7: 90-97. doi: 10.1016/j. bonr.2017.09.002
54. Fukumoto S. Targeting fibroblast growth factor-23 signaling with antibodies and inhibitors, is there a rationale?. Front Endocrinol (Lausanne). 2018; 9: 48. doi: 10.3389/fendo.2018.00048

55. Ichikawa S, Imel EA, Kreiter ML, et al. A homozygous missense mutation in human KLOTHO causes severe tumoral calcinosis. $J$ Clin Invest. 2007; 117: 2684-2691. doi: 10.1172/JCI31330

56. Topaz O, Shurman DL, Bergman R, et al. Mutations in GALNT3, encoding a protein involved in O-linked glycosylation, cause familial tumoral calcinosis. Nat Genet. 2004; 36: 579-581. doi: $10.1038 / \mathrm{ng} 1358$ 